$\begin{aligned} & \text { Final Report Certification } \\ & \text { for }\end{aligned}$
BRADA Number $\frac{\text { ornL02-06ét }}{\text { UT-Battelle, LLC }}$
and
Deere \& Company
(Participant)

\title{
Instructions:
}

Wark the appropriate statement in la or ib beiow with an "IX." Refer to the articles in the CRADA terms and conditions governing the identification and marking of Protected CRADA Information ( $\mathrm{PCl}$.

If no $\mathrm{PCl}$ is identified, the report will be distributed without restriction. If $\mathrm{PCl}$ is identified, the report distribution will be limited in accordance with the CRADA terms and conditions governing release of data. In all cases items 2 and 3 must be true. That is, the report cannot contain Proprietary information and a disclosure must be filed prior to release of the report.

This certification may either be made by using this form or may be made on company letterhead if the Participant desires. A faxed copy of this completed form is acceptable.

The following certification is made for the subject final report:

1. (a) $\square$ The final report contains information that qualifies as "Protected CRADA Information" (PCl). The PCl legend is printed on the report cover, and the $\mathrm{PCl}$ is clearly identified.

OR

(b) ХThe final report does not contain "Protected CRADA Information." The "Approved for Public Release" legend is printed on the report cover.

2. The final report does not contain Proprietary Information.

3. By the signature below, the Participant has no objection to the public distribution of the final report due to patentable information.

For the Participant:

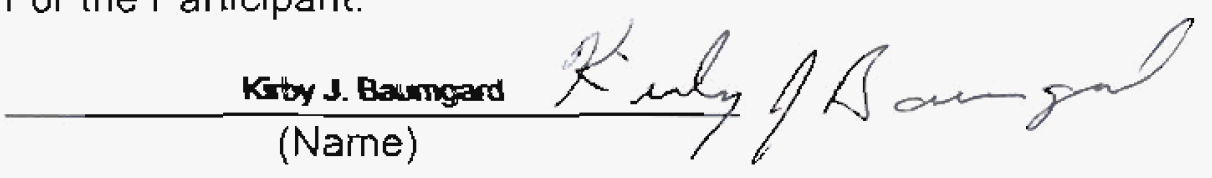

Project Mlanager, Adwanced Engine Technohogy

(Title)

$\frac{0212 \text { 2008 }}{\text { (Date) }} 8-12-08$


CRADA Final Report (ORNL-Deere \& Company, 2008)

CRADA Agreement Number ORNL02-0666

\section{Aftertreatment Technologies for Off-highway Heavy-Duty Diesel Engines}

A Final Report submitted to the Office of Energy Efficiency and Renewable Energy, Department of Energy, July 2008

DOE CONTACTS: GURPREET SINGH, STEVE GOGUEN

By

Mike Kass

Oak Ridge National Laboratory

Industrial Collaborators:

Kirby Baumgard

Deere \& Company

Rich Windsor

Deere \& Company 


\section{Contents}

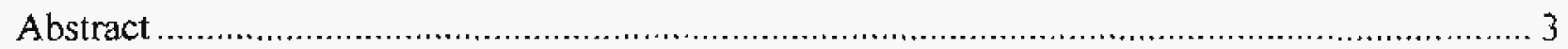

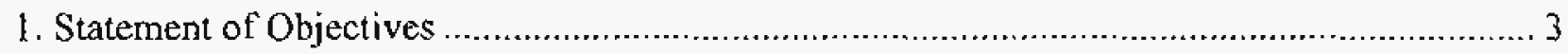

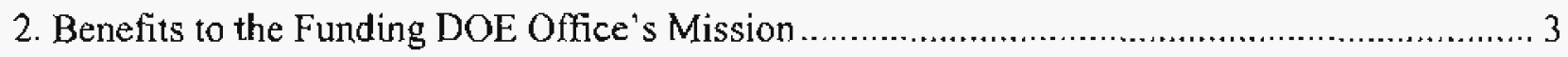

3. Technical Discussion of Work Performed by All Parties ........................................... 4

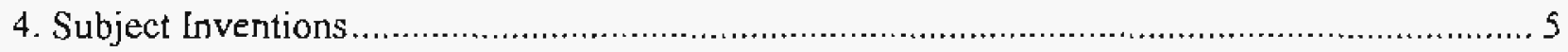

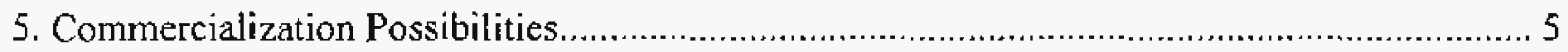

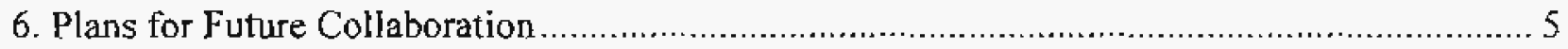

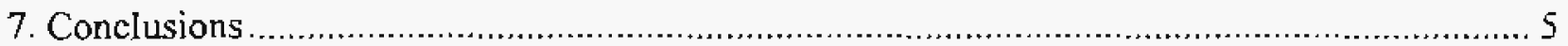

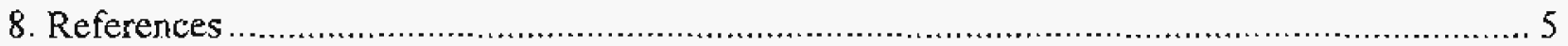




\begin{abstract}
The objective of this program was to explore a combination of advanced injection control and ureaselective catalytic reduction (SCR) to reduce the emissions of oxides of nitrogen (NOx) and particulate matter (PM) from a Tier 2 off-highway diesel engine to Tier 3 emission targets while maintaining fuel efficiency. The engine used in this investigation was a $20044.5 \mathrm{~L}$ John Deere PowerTechTM; this engine was not equipped with exhaust gas recirculation (EGR). Under the original CRADA, the principal objective was to assess whether Tier 3 PM emission targets could be met solely by increasing the rail pressure. Although high rail pressure will lower the total PM emissions, it has a contrary effect to raise NOx emissions. To address this effect, a urea-SCR system was used to determine whether the enhanced NOx levels, associated with high rail pressure, could be reduced to Tier 3 levels. A key attraction for this approach is that it eliminates the need for a Diesel particulate filter (DPF) to remove PM emissions. The original CRADA effort was also performed using No. 2 Diesel fuel having a maximum sulfur level of 500ppm.
\end{abstract}

After a few years, the CRADA scope was expanded to include exploration of advanced injection strategies to improve catalyst regeneration and to explore the influence of urea-SCR on PM formation. During this period the emission targets also shifted to meeting more stringent Tier 4 ernissions for NOx and PM, and the fuel type was changed to ulta-low sulfur Diesel (ULSD) having a maximum sulfur concentration of $15 \mathrm{ppm}$. New discoveries were made regarding PM formation at high rail pressures and the influences of oxidation catalysts and urea-SCR catalysts. These results are expected to provide a pathway for lower PM and NOx emissions for both off- and onhighway applications.

Industrial in-kind support was available throughout the project period. Review of the research results were carried out on a regular basis (annual reports and meetings) followed by suggestions for improvement in ongoing work and direction for future work. A significant portion of the industrial support was in the form of experimentation, data analysis, data exchange, and technical consultation.

\title{
1. Statement of Objectives
}

The following goals were pursued in this project:

1. Achieve Tier 3 NOx emission levels with fuel consumption at $195 \mathrm{~g} / \mathrm{kWh}$ or less.

2. Achieve particulate matter emission levels less than $0.02 \mathrm{~g} / \mathrm{kW}$ while operating the ureaSCR system.

3. Explore pathways to meet Tier 4 and retrofit solutions.

\section{Benefits to the Funding DOE Office's Mission}

In 2002 the Department of Energy was mandated to include off-highway engines as part of their existing Vehicle Technologies Program. As NOx and PM emissions from on-highway sources are being lowered the contribution of off-highway engines to the overall emissions inventory is becoming more pronounced. The diesel engine is considered the most fuel efficient powertrair. To enable further penetration of the Diesel engine into the off and on-highway markets, the 
emissions of NOx and PM must be reduced. This will aid in reducing the United States dependence on foreign oil. This directly supports the Office of Energy Efficiency and Renewable Energy's top priority. The objectives of this CRADA directly contribute to expanding Diesel engines into the market, thereby reducing foreign petroleum consumption.

\section{Technical Discussion of Work Performed by All Parties}

In the first phase of this collaborative effort, researchers from John Deere provided ORNL with a 2004 4.5 Liter 4045H PowerTech ${ }^{\mathrm{TM}}$ Diesel engine and hardware to support engine-dynamometer experimentation at the National Transportation Research Center (NTRC). John Deere researchers also provided an open controller and an on-site tutorial to enable manipulation of injection and rail pressure. In addition, John Deere procured a DOC and urea-SCR catalyst from Johnson-Matthey to be used in the initial set of experiments, which also included providing ORNL with a Bosch urea dosing unit capable of precise metering of urea into the exhaust.

ORNL researchers installed the engine and baseline operation performance was compared with the results obtained from operation at the John Deere Product Engineering Center. The open controller was installed and operated with technical support from John Deere researchers. In order to make the Bosch urea dosing unit operational, ORNL researchers had to prepare a wiring harness and setup the maps to drive electronic control unit associated with the dosing unit. The $D O C$ and urea-SCR catalyst were installed last and, once this step was completed, baseline experimentation of the urea-SCR system and rail pressure study was initiated.

An extended series of experiments focused on the influence of rail pressure on NOx, PM and fuel efficiency showed that increasing the rail pressure had little influence on the overall fuel efficiency associated with combustion, while increasing and decreasing the NOx and PM, respectively. One novel phenomena that we discovered was that although the total PM was reduced by higher fuel injection pressure, the soluble organic fraction (SOF) of the PM increased to a maximum value and then decreased with increasing pressure. This effect goes against the convention and represents an important aspect of high fuel injection pressures that needs to be considered when developing exhaust aftertreatment systems.

We found that the approach of using high rail pressure to lower PM and urea-SCR to reduce exhaust NOx emissions was an effective approach for meeting Tier 3 standards for NOx and PM for off-highway vehicles. However, final Tier 4 NOx emissions could not be met using this approach using the existing catalyst and setup. A pathway to achieve Tier 4 NOx emissions was developed that included increasing the size of the urea-SCR catalyst and implementing a thermal managernent technology to maintain the catalyst temperature in the optimal window.

In the second phase of the CRADA, ORNL, with technical support from John Deere, examined the influence of urea-SCR on PM formation. The total PM was lowered by the DOC, but further reduced by the urea-SCR catalyst. This effect occurred even while urea was being applied to the catalyst. This effect is considered significant and has not been reported elsewhere. Analysis of the PM indicated that the SOF portion of the total PM was oxidized by the urea-SCR catalyst and that oxidation was taking place even while reducing NOx emissions during urea application. This result is expected to be incorporated into current modeling efforts to better understand 
aftertreatment performances and advance the development of new aftertreatment systems.

Further details regarding the activities performed under the CRADA can be found in the provided references.

\section{Subject Inventions}

No inventions were filed under this CRADA.

\section{Commercialization Possibilities}

Commercialization of the NOx/PM approach could be achieved today to meet Tier 3 emissions. However, in order to meet Tier 4 emission levels, which start in 2011, further improvements in the performance of the urea-SCR systern will need to be made. John Deere and other companies are likely to pursue certain aspects of this approach, but since U. S. Department of Energy no longer supports off-highway efforts, ORNL will not be involved under the current guidelines. Diesel engine manufacturers are keen to pursue technologies that eliminate the need an aftertreatment device since these systems increase cost and complexity of the vehicle. Approximately $5-10$ years of further research may required for the previously mentioned scenario to become a reality. Therefore, the commercialization of this technology is at least five years away.

\section{Plans for Future Collaboration}

ORNL and John Deere are continuing informal collaborations in the areas of combustion and aftertreatment. However, since off-highway engines are no longer part DOE's vehicle technologies program, the CRADA is being discontinued. John Deere maintains a high interest in combustion and exhaust aftertreatment and future collaborations are anticipated.

\section{Conclusions}

A strategy of combining advanced combustion to lower PM with urea-SCR to reduce NOx exhaust emissions was found to be effective for enabling a Tier 2 Diesel engine to meet Tier 3 emissions for off-highway Diesel engines. The collaboration between ORNL and John Deere successfully installed a beavy-duty diesel engine and sophisticaled aftertreatment systern to accomplish significant reductions in PM and NOx emissions, and a pathway to meet Tier 4 emissions using this approach was developed. This collaboration led to the discovery that high rail pressures can initially increase the SOF of the total PM, followed by decreasing SOF at still higher pressures. The urea-SCR catalyst also contributes to PM reduction by nearly completely oxidizing the SOF; this effect occurs simultaneously with NOx reduction under the application of urea to the catalyst.

\section{References}

M. D. Kass, N. Domingo, J. M. E. Storey, S. A. Lewis, and K. Baumgard, "Influence of High Rail Pressure on PM and NOx Formation and the Conversion Efficiency of a Urea-SCR System on a Heavy-Duty Diesel Engine," to be published at the 2008 Fall SAE Powertrain and 
Fluids Meeting in October.

M. D. Kass, "Selective Catalytic Reduction Technologies and Their Influence on NOx Emissions and PM Formation in an Off-Highway Application," Emission Reduction Systems for Off-highway Applications Conference, Car Training Institute, Stuttgart, Germany July 12, 2008. (Invited lecture) 